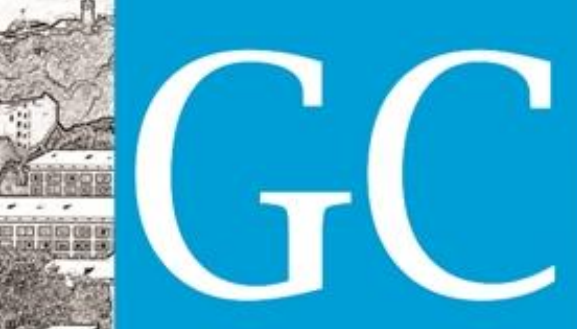

\title{
Revista Nacional de
}

Gerenciamento de Cidades

\section{Avaliação da ambiência urbana: \\ Estudo de caso em espaço urbano em Passo Fundo, RS}

Evaluation of the urban environment:

Case study in urban space in Passo Fundo, RS

Evaluación del entorno urbano:

Estudio de caso en espacio urbano en Passo Fundo, RS

Mirian Carasek

Professora Mestre Arquiteta, UPF, Brasil miriancarasek@upf.br

Juan José Mascaró

Professor Doutor Arquiteto, UPF, Brasil

juan@upf.br 


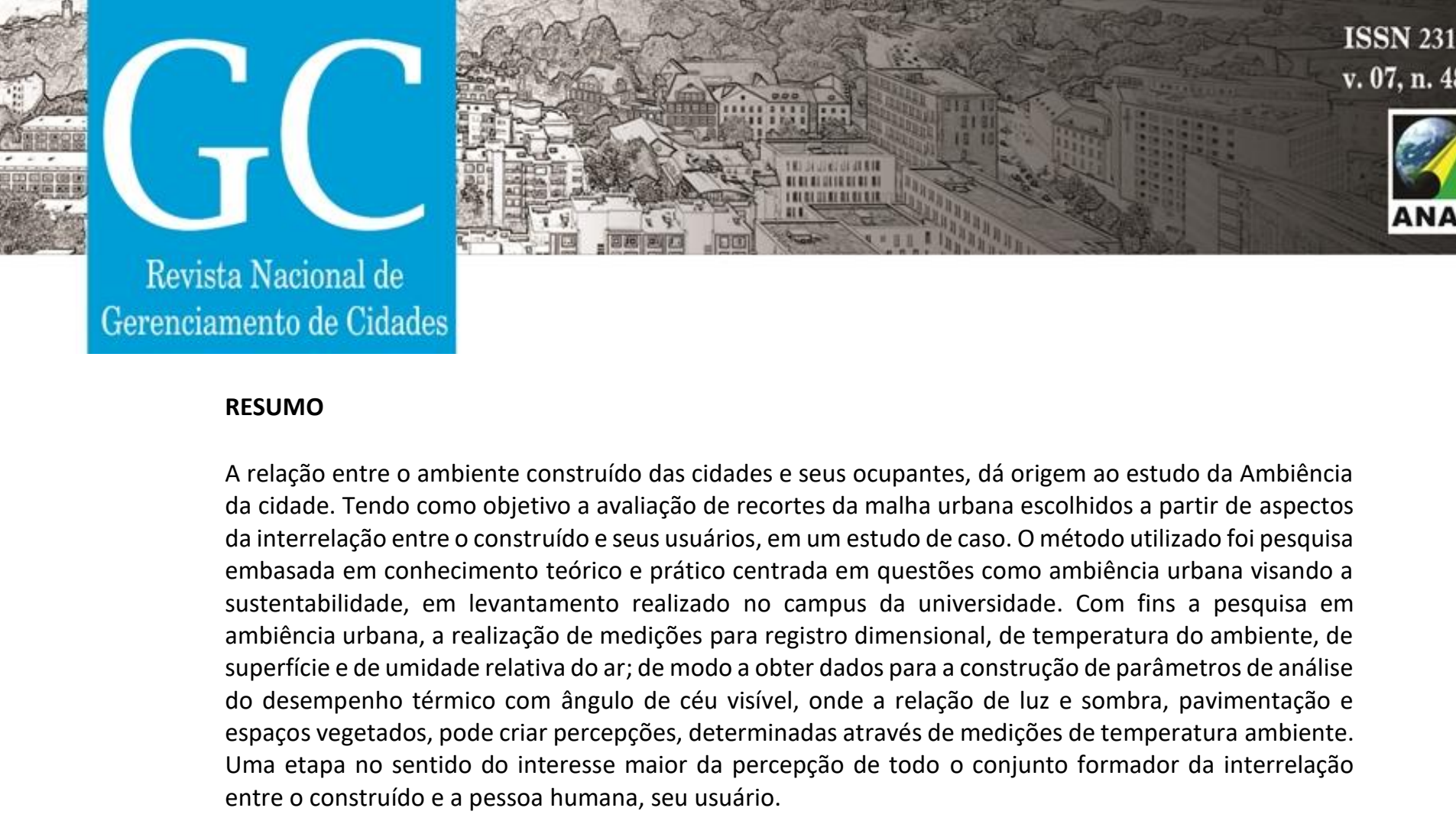

PALAVRAS-CHAVE: Ambiência urbana. Diagnóstico. Passo Fundo.

\section{ABSTRACT}

The relationship between the built environment of the cities and their occupants, gives rise to the study of the Ambience of the city. With the objective of evaluating the urban mesh cut-outs chosen from aspects of the interrelationship between the built and its users, in a case study. The method used was research based on theoretical and practical knowledge centered on issues such as urban environment aiming at sustainability, in a survey carried out on the campus of the university. With the purpose of research in urban environment, measurements for dimensional registration, ambient temperature, surface and relative humidity of the air; in order to obtain data for the construction of thermal performance analysis parameters with visible sky angle, where the relation of light and shade, pavement and vegetated spaces, can create perceptions, determined through measurements of ambient temperature. A step in the direction of the greater interest of the perception of the whole formative group of the interrelation between the constructed one and the human person, its user.

KEY WORDS: Urban environment. Diagnosis. Passo Fundo.

\section{RESUMEN}

La relación entre el ambiente construido de las ciudades y sus ocupantes, da origen al estudio de la Ambiencia de la ciudad. Con el objetivo de la evaluación de recortes de la malla urbana elegidos a partir de aspectos de la interrelación entre el construido y sus usuarios, en un estudio de caso. El método utilizado fue una investigación basada en el conocimiento teórico y práctico centrado en cuestiones como el ambiente urbano para la sostenibilidad, en un estudio realizado en el campus de la universidad. Con fines de investigación en ambiente urbano, realización de mediciones para registro dimensional, de temperatura del ambiente, de superficie y de humedad relativa del aire; para obtener datos para la construcción de parámetros de análisis del desempeño térmico con ángulo de cielo visible, donde la relación de luz y sombra, pavimentación y espacios vegetados, puede crear percepciones, determinadas a través de mediciones de temperatura ambiente. Una etapa en el sentido del interés mayor de la percepción de todo el conjunto formador de la interrelación entre lo construido y la persona humana, su usuario.

PALABRAS CLAVE: Ambito urbano. Diagnóstico. Passo Fundo. 



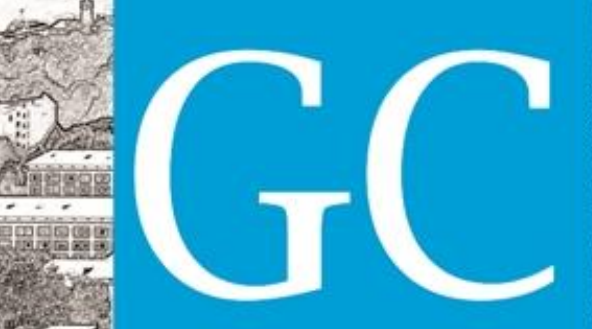

\section{CAMPUS DA UNIVERSIDADE DE PASSO FUNDO COMO ÁREA DE ESTUDO}

Passo Fundo ( $28^{\circ} 15^{\prime} \mathrm{S}, 52^{\circ} 24^{\prime \prime} \mathrm{W}$ e $687 \mathrm{~m}$ de altitude), conta com 783,6 km², população estimada [2018] de 201.767 pessoas e densidade demográfica [2010] - 235,92 hab/ $\mathrm{km}^{2}$. Está localizado na Zona Climática fundamental temperada, apresentando clima do tipo fundamental úmido e variedade específica subtropical (Cfa). Desse modo, o clima local é descrito como subtropical úmido ( $\mathrm{Cfa}$ ), com chuva bem distribuída durante o ano e temperatura média do mês mais quente superior a $22^{\circ} \mathrm{C}$ em janeiro e a mais baixa $12,7^{\circ} \mathrm{C}$ no mês de junho; com temperaturas máximas, em torno de $28^{\circ} \mathrm{C}$ e mínimas de $9^{\circ} \mathrm{C}$. As precipitações registradas entre $118 \mathrm{~mm}$ e $170 \mathrm{~mm}$. O índice de umidade relativa na cidade, pode ser considerado constante, oscila entre 67\% e 76\%; o período de insolação (em horas), é de 2329,6/ ano (EMBRAPA, 2019; SEMC, 2002; IBGE, 2019).

Nas últimas décadas, a cidade afirmou-se como sexta economia do Rio Grande do Sul e capital do Planalto Médio Gaúcho, por ser polo universitário, referência de atendimento em saúde e contar com dinâmica atividade no setor de serviços, no comércio, na indústria e no agronegócio. O estudo foi realizado no Campus 1 da Universidade de Passo Fundo, em trecho consolidado, edifícios com ampla circulação de pessoas e veículos. A Universidade de Passo Fundo é uma instituição de ensino superior privada, fundada em 1968 na cidade de Passo Fundo. Além de Passo Fundo, a UPF possui campi em outras seis cidades do norte do estado. Sendo que já formou mais de 75 mil profissionais desde a fundação.

\section{DESENVOLVIMENTO DO TRABALHO: Medições, resultados e diagnóstico}

Os pontos escolhidos estão localizados próximos aos edifícios G1, G2 e G3, como se pode ver no mapa nas figuras 1 e 2 . Os pontos estão localizados próximos uns dos outros, porém, apresentam comportamentos diferenciados devido à posição solar, com maior, ou menor, índice de sombreamento; e, presença, ou ausência, de vegetação e árvores. 


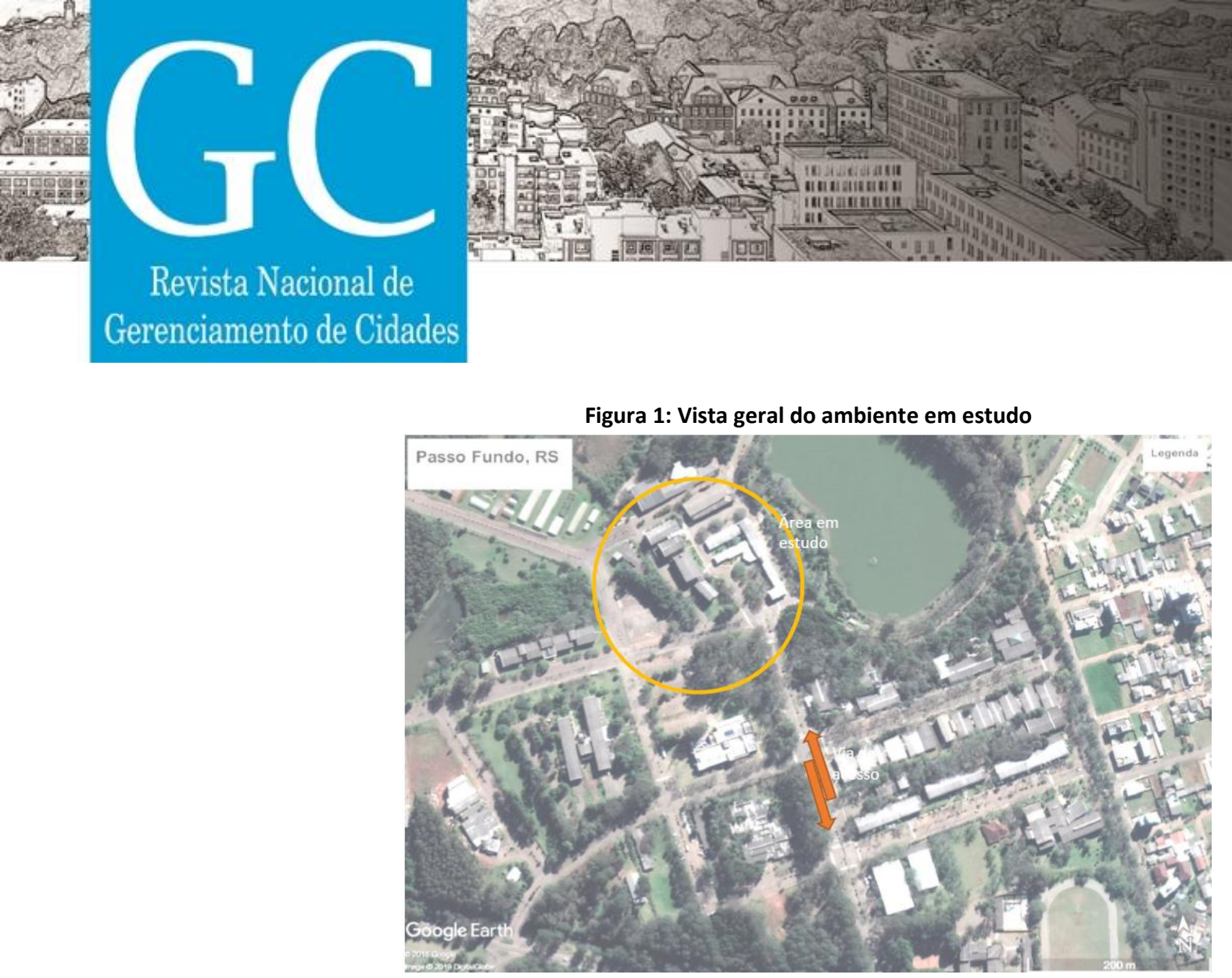

Fonte: Adaptado de Google Earth pelos autores, 2019

Foram realizadas medições de temperatura e umidade do ar e temperatura da superfície, com o auxílio de termohigrômetro e termômetro de superfície. Sendo que a coleta de dados foi realizada nas diferentes situações possíveis para cada ponto, no meio da tarde, no mês de abril.

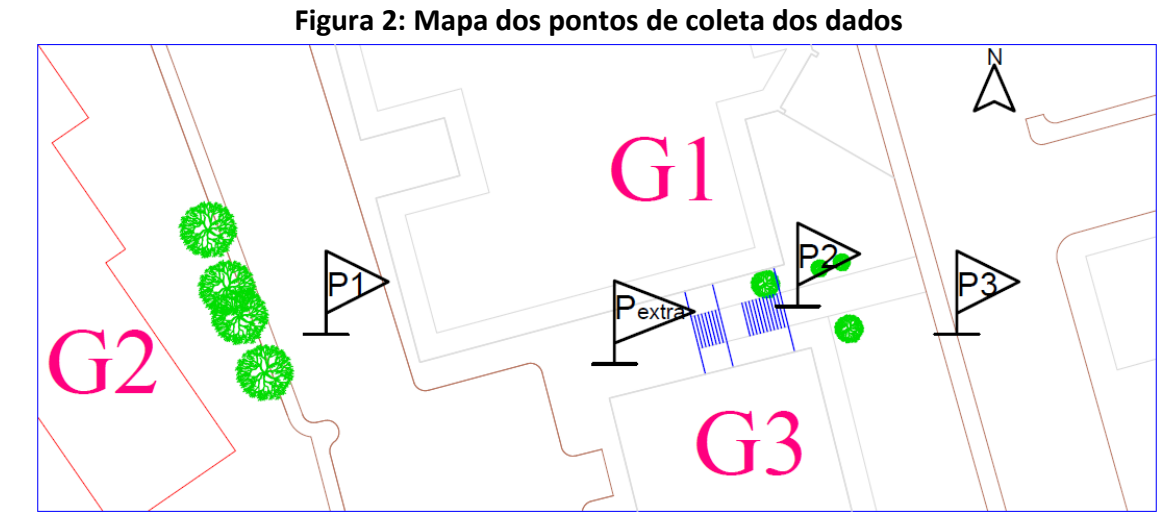

Fonte: Autores, 2013

\section{Ponto 1}

Caracterização: Este ponto está localizado numa área próxima ao estacionamento existente; próximo a árvores de grande porte; apresenta incidência solar pela tarde, como se pode observar pelas fotos da Figura 3. As fotos apresentam a primeira impressão do usuário, em relação ao recorte da malha urbana, que se forma com as edificações presentes. 

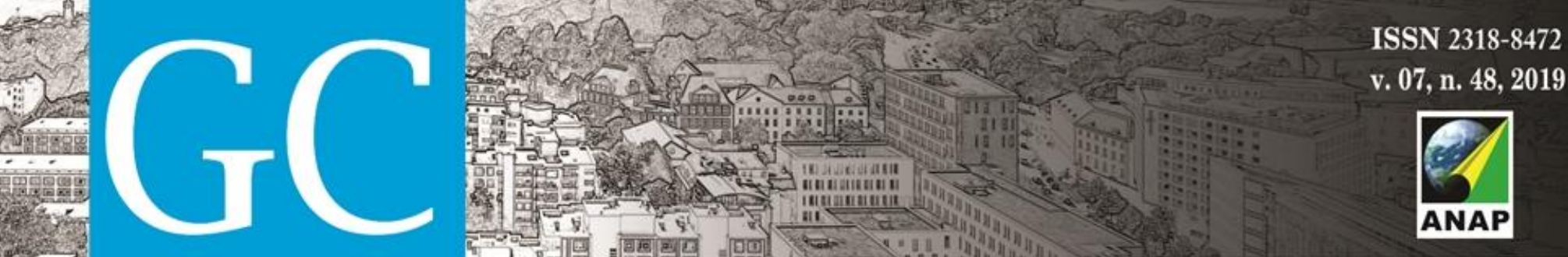

\section{Revista Nacional de}

\section{Gerenciamento de Cidades}

Figura 3: Características visíveis no ponto 1. (a) Ponto 1, em esquina. (b) a nordeste: Calçada sem arborização nem grama. (c) a sudoeste: árvores e declive em grama.

(a)

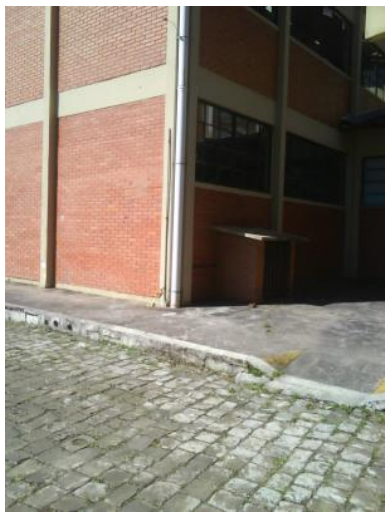

Fonte: Autores, 2013 (b)

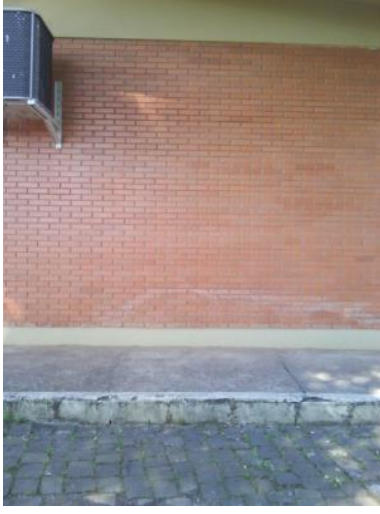

(c)

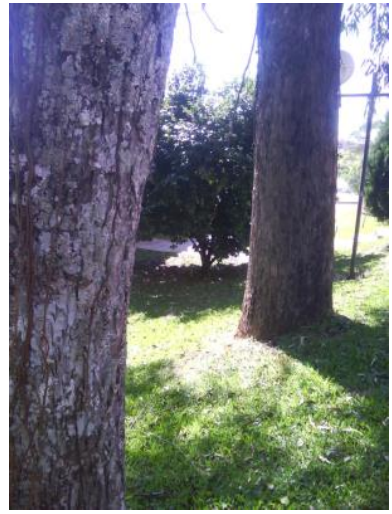

Medições e diagnóstico presencial: Este ponto tem como características, via com largura de 6,50 $\mathrm{m}$ e calçadas de 1,60 m e 1,20 m, possuindo arborização em apenas um dos lados, conforme mostrado abaixo (Figuras 3(c) e 4). O calçamento, no lado sem arborização, é de concreto claro, enquanto no outro lado da rua é de pedras de basalto. As árvores existentes com altura de aproximadamente $6 \mathrm{~m}$, são em sua maioria, eucaliptos (Eucalyptus $s p$ ).

As medições permitem a representação gráfica apresentada no corte esquemático e constatações, como apresentadas em seguida. A relação entre altura e largura da via $(\mathrm{h} / \mathrm{d})$ expressa por: $\frac{h}{d}=\frac{5}{14.3}=0,35$; sendo possível calcular o angulo de céu visível.

Figura 4: Corte esquemático do ponto 1.

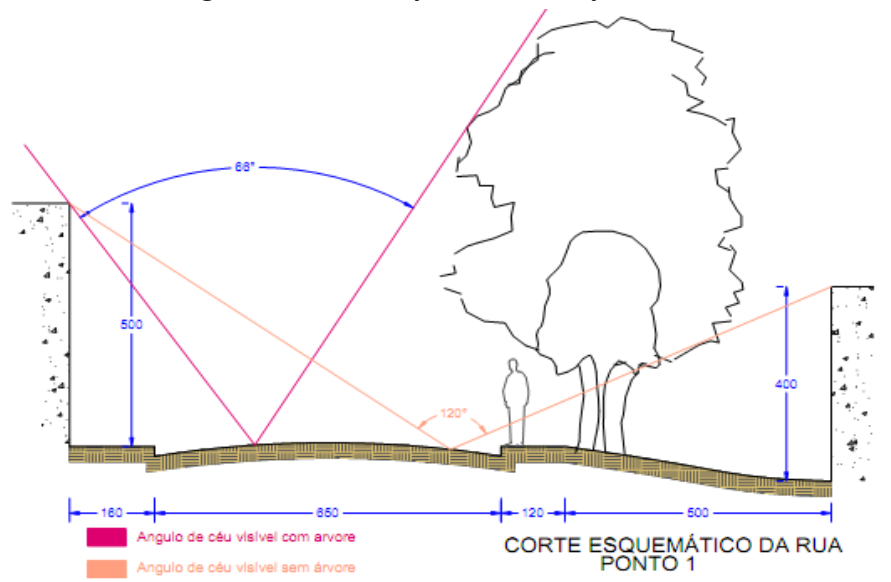

Fonte: Autores, 2013 


\section{Revista Nacional de} Gerenciamento de Cidades

Figura 7: Corte esquemático da via, no ponto 2

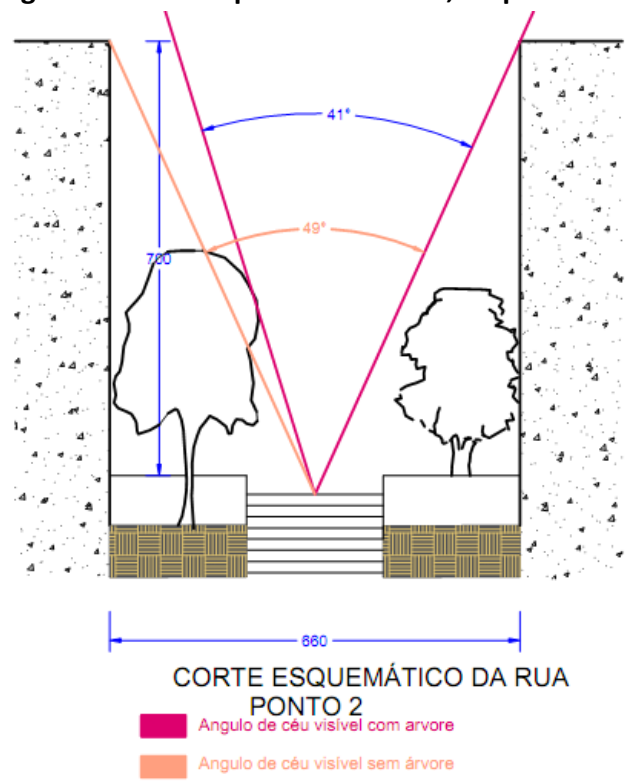

Figura 8: Espaçamento entre as árvores no ponto 2

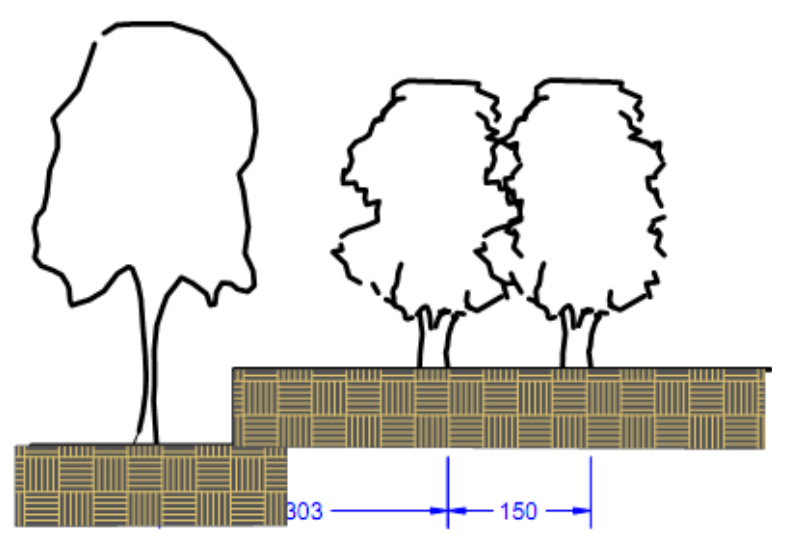

Fonte: Autores, 2013

Medições e diagnóstico presencial: De modo diferenciado do ponto 1, as árvores são de menor porte e em menor quantidade (Figuras 7 e 8). A relação entre altura e largura da via (h/d) expressa por: $\frac{h}{d}=\frac{7}{6,6}=1,1$.

Os dados de temperatura e umidade do ar, bem como temperatura da superfície, foram coletados e reproduzidos na tabela abaixo, conforme as descrições: $\mathrm{P} 1=$ calçada 1 ao sol; P2= calçada 2 com arborização, à sombra; P2'= calçada 2, entre árvores (Tabela 2).

Tabela 2: Dados coletados junto ao ponto 2

\begin{tabular}{|c|c|c|c|}
\hline & $\begin{array}{l}\text { Temperatura } \\
\text { ambiente }\end{array}$ & $\begin{array}{l}\text { Umidade relativa } \\
\text { do ar }\end{array}$ & $\begin{array}{l}\text { Temperatura na } \\
\text { superfície }\end{array}$ \\
\hline $\begin{array}{l}\text { P } 1 \\
\text { calçada } 1 \text { ao sol }\end{array}$ & $25,6^{\circ} \mathrm{C}$ & $31 \%$ & $36^{\circ} \mathrm{C}$ \\
\hline $\begin{array}{l}\text { P2 } \\
\text { calçada } 2 \text { com } \\
\text { arborização, à sombra }\end{array}$ & $25,3^{\circ} \mathrm{C}$ & $31 \%$ & $21^{\circ} \mathrm{C}$ \\
\hline $\begin{array}{l}\text { P 2' } \\
\text { calçada 2, entre árvores }\end{array}$ & $25,2^{\circ} \mathrm{C}$ & $30 \%$ & $21^{\circ} \mathrm{C}$ \\
\hline
\end{tabular}

Desempenho térmico. A representação do corte esquemático permite definir os ângulos de céu visível, porém, neste ponto de análise, a presença da vegetação reduz a diferença entre os ângulos de incidência de sol; de $49^{\circ} \mathrm{C}$ para $41^{\circ} \mathrm{C}$, quando da presença da árvore. $\mathrm{O}$ desnível entre as floreiras vegetadas, como percebido na figura 7 , delimita a pequena diferença de 



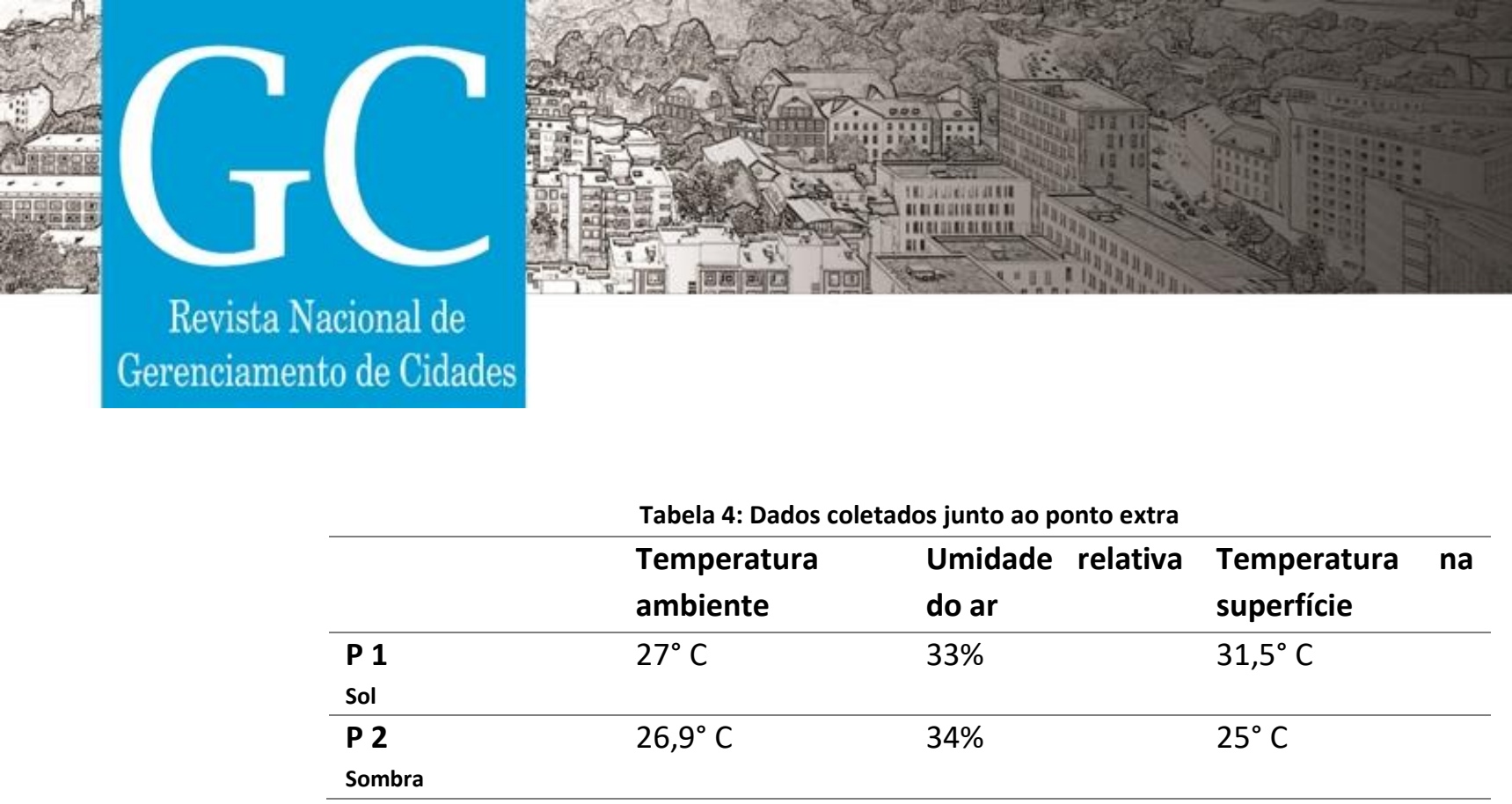

Fonte: Autores, 2013

Desempenho térmico. Neste ponto, onde há menor incidência de luz solar, criando sombras mais acentuadas, a variação na medição da temperatura ambiente pode ser considerada constante, o mesmo ocorrendo com a umidade relativa do ar. A temperatura de superfície registrou variação mais acentuada, de $6,5^{\circ} \mathrm{C}$.

\section{Ponto 3}

Caracterização: Este ponto tem calçadas mais largas que as anteriores e há presença de gramado de um dos lados. Na figura 11 (a) e (b), podem-se ver passeios (com e sem grama), onde foram feitas as tomadas de temperatura (ambiente e de superfície) e de umidade relativa do ar que aparecem na tabela 3. O leito da rua, aqui é de paralelepípedos e as calçadas dos dois lados são revestidas com blocos de basalto. A fachada do lado em que há gramado é de tijolos aparentes e do outro lado, sem grama, é rebocada e pintada de cor clara.

Figura 11: fotografias do ponto 3: (a) leito carroçável, calçada e gramado e (b) gramado, calçada e via de veículos
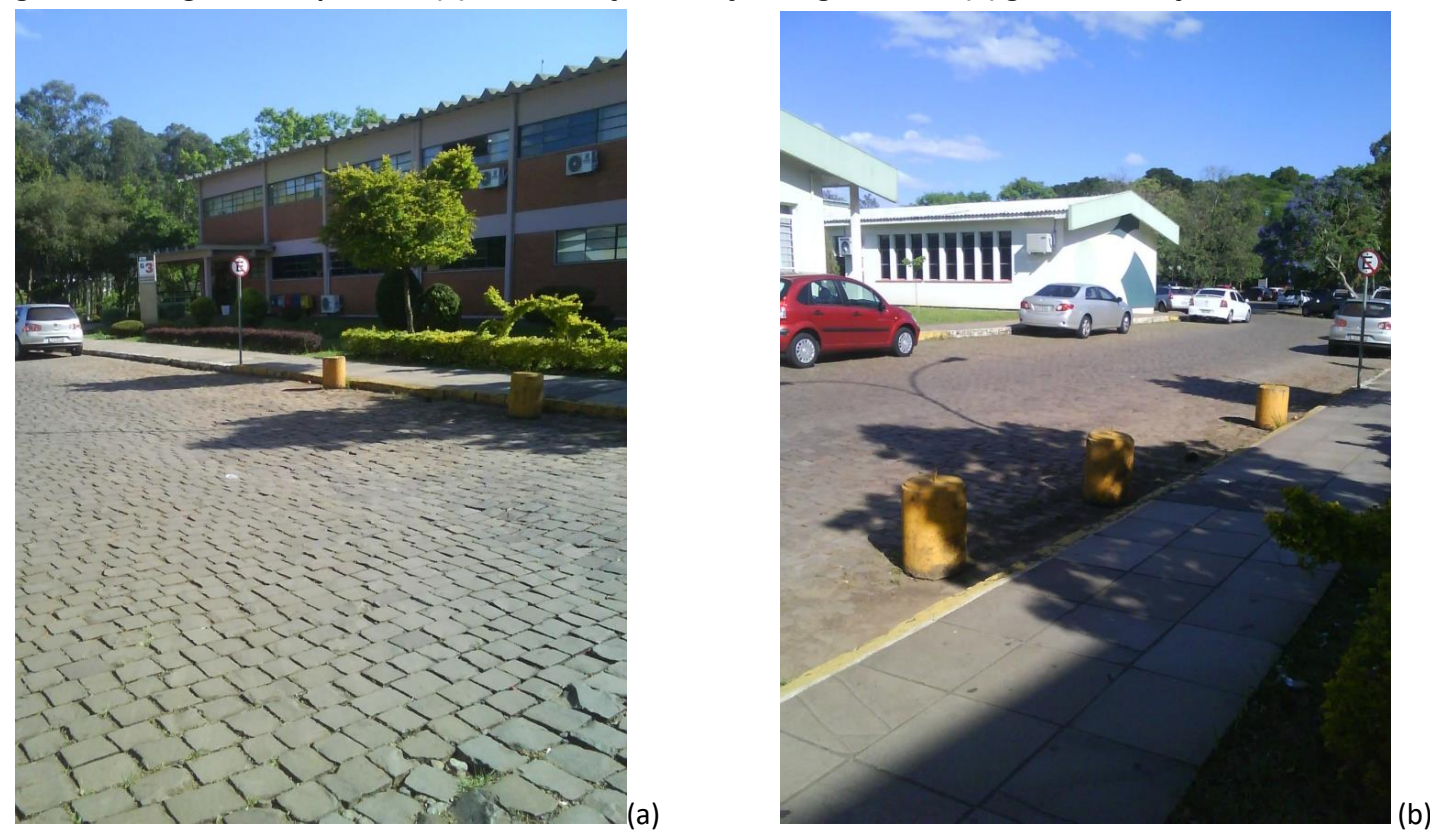

Fonte: Autores, 2013 
